\title{
Developing Speaking Skill at Secondary and Higher Secondary Levels: Problems and Few Recommendations
}

\begin{abstract}
NIPA BHATTACHARJEE
Although much has changed since Communicative Approach has been adopted in ELT of Bangladesh in the beginning of this new millennium, still speaking is in many ways an undervalued skill at secondary and higher secondary level. It is true that, speaking skill is more highlighted than ever in line with the new changes of curriculum design and with each chapter tasks on speaking have been incorporated and our young learners' of schools and colleges are more eager to improve their speaking skill in English. But in reality there is no practice and reflection of this skill. Still, inside the classroom, the main focus of teaching and learning is on traditional reading and writing; we see, there is no initiative to develop speaking and it is immensely ignored as before. Our learners' rarely get any opportunity available for them to continue to practice English inside the classroom and the outside society provides no 'lessons' in authentic practice situation where language acquisition can happen through interaction. As the conditions for natural acquisition have no scope, it is the classroom which should employ students' with different speaking activities.
\end{abstract}

In my paper, I intend to analyze the psychological factors that prevent students from being vocal in the classroom activities, especially at schools and colleges and the common speaking problems faced by Bangladeshi learners in and outside the classroom. I would also like to address some of the incongruities in speaking activities that are presently being used in the course books of SSC and HSC levels designed by NCTB. Finally, I will try to offer some recommendations which are much needed in our context. In my paper, I have excluded that section of people who have frequent access to the English speaking community and have the privilege of using English in and outside the family and the English medium schools where English is a medium of instruction and also, very few institutions in and outside the capital 
where English is used. My focus of discussion is limited to the general students who have come from Bangla medium school and college.

Speaking activities within the artificial limits of classroom can be a negative experience as far as certain affective factors are involved. Speaking something in front of the fellow students is directly related to high anxiety. Students are severely embarrassed and inhibited when opportunities arise for them to speak. Again, if learners find their peers are more proficient in speaking compared to them, they tend to become anxious, and it results in remaining silent and taking 'nothing to say' (Rivers 192) expression at the moment. Some students are very conscious about their limitation of language and they feel insecure in the knowledge they do have. They prefer not to talk and don't want to be ridiculed or censured in front of the whole class. Students may feel that they are presenting themselves at a much lower level of cognitive ability than they really possess (Hedge 292), so to keep their image better to the rests of the students in the class, they do not want to take the risks of speaking.

Then, students' personality factors (extrovert, introvert, talkative, shy, taciturn) affect their performance in the oral production. There is a widely held view that extrovert students outperform the introvert in the oral work, possibly because the extroverts are outgoing in nature, thereby they can have much interaction with the people around them and subsequently, practice occurs, increasing fluency.

In our context of classroom speaking, all these factors are very much true. Learners have a very little space provided for them to be vocal in the classes as still our classroom is teacher oriented. The puritan 
and dominating attitude of the teachers' also debar students not to participate in the learning activities. Also, teacher's biased attitude toward the best student or a group of good students hinders the dull ones not to talk in the classroom.

The teacher must take all these factors into his consideration and ensure all students' equal vocal participation in the classroom activities and create a friendly and relaxed atmosphere inside the classroom where every student feels at ease and ready to contribute according to their ability.

Now let us see, as far as speaking skill is concerned, at schools and colleges, what common problems Bangladeshi students face in and outside the classrooms.

1. The first and foremost problem of speaking on part of the students is fear and lack of confidence. The fear is most acute, especially in rural areas where $70 \%$ of our total populations live and to the students of this area, English is an alien subject to study. Their fear of English is so deep rooted that if you ask them a very simple question like 'what is your name?' they lose their faces and stop talking. Inside the classes, students are intimidated and frightened by the fact that they will be taught a language which is alien by its very nature; from the first class they never feel at home with the foreign language.

2. Sudden introduction of Communicative Language Teaching to Bangladesh has brought sudden changes in the curriculum, so in the field of ELT. But the qualitative changes in teaching have not been ensured yet. Moreover, though substantial changes have been made to teaching and learning method, the teaching techniques remain the same. Still, many of the teachers go to 
class, select a passage from the text, start reading it aloud, translate the text into Bangla, and ask students the meaning of some unfamiliar words and tell them to answer the questions following the passage. They never try to promote fluency engaging students in real life activities like-role play, simulation, presentation, free discussion, debate, group work, pair work, etc, prescribed by the text books.

3. At the age at which many of our learners start studying English, by the time they become almost expert in expressing their needs and demands in their mother tongue. So, in the classroom students find it a bit awkward and frustrating to use the language to express themselves with childish structure and with a very nominal amount of vocabulary common to them and the language what they are being taught is apparently of no use outside the classes. At the same time, the influence of mother tongue is so strong and overpowering that it interferes with the second language acquisition, so in the class of speaking skill.

4. Up to H.S.C, provision is not kept to judge students' oral performance; no tests are given to them to assess their proficiency in speaking. In both SSC and HSC levels, we have respectively 200 marks allocated to English. But the fact is that, learners never attend any speaking classes nor do they appear in any viva or oral part. The mystery, how far they are learning to speak the language, remains unknown and unsolved until they attempt to further studies.

5. Motivation is some kind of internal drive which pushes someone to do things in order to achieve something (Harmer 51). If the learner enters the course with positive motivation, 
learning becomes faster with positively motivated students. When it comes to the question of arousing motivation among the students through the classes, learning becomes difficult and it defers. In Bangladesh, what happens? At the early stage, students are not aware of why they are forced to learn and use English. So, learners take English as a course of study like other subjects, such as math, economics, social science, etc. Their goal of learning English is passing examinations to advance education i.e. they are instrumentally motivated. With the advancement of their age, they become able to understand why they need to learn better English. Again this is to find better jobs, to study abroad or to build rapport with some elite people. Motivation is lacking throughout their academic life and the teachers never feel the urgency of motivating them in a positive manner and making them understand the importance of English specially speaking skill.

6. Then, exposure to speaking situations is extremely limited within the confines of classroom. Students get a very limited access to English outside the classroom where they spend most of their time with their family, friends and the community. In an EFL context like Bangladesh, outside society does not provide any practical situation for the learners to get engaged in and to practice the oral form of communication. As there is almost no need for speaking English outside the classroom, learners do not treat English as a means of communication rather their interest mainly lies in achieving some goals. Even in educated families, culture is not developed to speak in English among the family members.

7. Harmer sees 'reception as a part of production' (251). If you want to produce something, some kind of practical input is a 
must, whether it is written or spoken. Speaking is something which is directly related to listening. "Conversation between two people is a blend of listening and speaking. Reception and production are so bound up together that we should not have students practice skills in isolation" (Harmer 251). But in the context of our country, our learners are never exposed to listening so that they do not come to know how to manage interaction, use fillers, develop phonological features, and social and cultural rules that are involved in each situation etc. We have a wrong notion about the purpose of listening that it is only related to the idea of developing perfect pronunciation, stress and intonation. I would like to say, our goal in teaching speaking is not developing accurate stress, perfect intonation, and native-like pronunciation; rather it is adequacy of fluency and communicative effectiveness that becomes the focus of speaking skill. It is possible to express one's intention, desire, demand, view, ideas without elegant pronunciation. But, at the same time, we cannot deny the fact that, 'very poor' or 'poor' pronunciation with strong dialectical influence does not sound good to the ear, and it indicates the lack of knowledge of English of the speaker, or sometimes faulty pronunciation may even lead to miscommunication. But, in the context of Bangladesh, our learners are never exposed to formal listening in the classroom.

8. Teacher training is central to teacher development. In Bangladesh, our teachers are rarely trained in teaching, let alone speaking. Most of the teachers are not well-spoken. They usually do not receive any training to teach the speaking skill specifically, so they are unable to carry out different speaking activities, such as pair work, group work, role play, free 
discussion, etc. Conditions are horrible in the rural and remote areas where English is taught through Bangla or lecture of English is given in Bangla.

9. Due to lack of resources, our learners' are not equipped with the logistic supports needed to develop speaking skill inside the classroom.

10. The government policy and attitude towards English is sometimes responsible for the underdeveloped speaking skills among students. Recurrent changes in the curriculum and over emphasis on mother tongue after independence have contributed to the fact that English is no more the official language or the only medium of instruction in educational institute as it was before liberation. In Bangladeshi context, as the students do not need to take the help of English to express their views, thoughts and demands in everyday communication and they have alternative Bangla available to them, so they are unlikely to improve their speaking skill.

Besides, the social status and the way of his/her upbringing also determine the level of proficiency of speaking attained by the students.

In this section, I have tried to point out some incongruities in speaking materials which are often suggested and frequently being carried out with the purpose of promoting speaking inside the classroom, and I am convinced to believe that these activities are inadequate to meet the need of the students and help them develop communicative efficiency in speaking and they rarely improve fluency, which is one of the desirable goals of speaking. 
1. Most of our speaking materials in the texts of secondary and higher secondary levels are devoted to structured output activities, like short structured question, true false question, and fill in the blanks etc. No doubt, these materials are designed to integrate speaking with other skills, but if someone notices carefully, s/he will see each of these activities mainly focus on specific forms or structures of grammar. They are more like drills than like real communication. In structured question, as we have, only one possible answer, so students are having less chances in elaborating and extending their ideas. Once the answer is given, learners cannot talk much on that topic. More than this, giving answer to particular question does not reflect the language that is needed outside the class room in a practical situation. In real communication, participants must manage uncertainty about what the next person will say. But in structured question, there is no uncertainty about how to manage the interactions. Thus, none of these activities promote fluency rather they judge the ability to understand the text as a whole.

Again, filling the blanks and true false questions are very much like short structured question. Here, answers are predetermined. In filling in the gaps activity, students have only two possible options, 'true' or 'false' and they do not need to meet the challenges by negotiating meaning or facing uncertainty. Increasing oral skill and fluency through true false activity is really very constricted and confined. It does not maximize the fluency rather it demonstrates the power of comprehending the reading text.

2. Our English course book of higher secondary level lacks the sequential orders which are essential to maintain the conformity 
of speaking and going from one stage to another. Suppose, when students are able to introduce themselves using present simple, they will be moving on to next topic, such as getting information about others focusing on the similar item of language. Once they demonstrate their proficiency in certain linguistic form, there would be a gradual shift in emphasis on communicative efficiency relating to that particular form. But unfortunately, the contents of our English course books are randomly selected and they pay no systematic attention on sequential order of speaking tasks.

3. Communicative language teaching in ELT has shifted the focus from form to meaning, from structure to communicative side of language. In the preface to 'English for Today' for the classes 11-12, Professor Md. Yousuf Farook, chairman of NCTB writes 'The emphasis on the communicative approach, however, does not disregard the role of grammar.' Still, in the classes, discussion on grammatical items has been put aside. Without being accurate, students cannot be expected to be vocal and fluent. As there is guided focus on forms, students tend to focus on 'what to say rather than how to say'. Now-a-days, students somehow have got the impression that language means 'something spoken' (Rivers 161). This trend is so much popular among the young generation that, they often infuse English words, phrases, and sentences in their Bangla speech overthrowing English grammar. So, they develop what Skehan calls 'undesirable fluency'. (qtd in Hedge 160)

4. The real communication takes place through accomplishing a task, such as conveying a telephone message, giving an opinion, greeting, introduction and making acquaintance etc. For successful completion of the tasks, learners need to negotiate 
meaning through interaction at times between student-teacher and sometimes among themselves. Prof. Md. Yousuf Farook writes that the book is based on the principle that guided the writing of English for Today books from class 6 onwards ----the principle of learning a language by actually practicing it. But the fact is that, the existing curriculum of secondary and higher secondary levels lacks the insights to develop speaking skills actually by practicing and experimenting with the language. The theoretical emphasis has overshadowed the much needed practical side and missed out on the scope for practicing language what students need in everyday life to encounter different situations.

5. The assigned teachers, teaching at primary and tertiary levels, are the products of grammar translation method. They believe that if the learners are proficient in reading and writing, they will be able to speak fluently if situations do arise; no guided practice is needed. Having this mindset, they never encourage learners' to speak in the classroom. Their ideas are wrong. Fluent speaker will not be produced overnight. It is a matter of practice and it's a major responsibility on the part of the teachers to give the students an enormous opportunity to practise speaking in the classroom environment so that they can attain proficiency.

Making a way out of this speaking problem is difficult, if not impossible. With the view to developing speaking along with other skills, like writing, reading and listening, CLT has been imported to Bangladesh and various speaking activities have been adopted for the improvement of the learners. The changes in the curriculum are 
obvious. But what is more needed is effective implementation of these activities in the classroom alongside in practical field. Besides, I believe in, making some necessary changes in the curriculum and education policy as well as bringing out some qualitative changes in the caliber of teachers. Situations will be improved if the following things can be done.

1. I pointed out earlier, at present, up to HSC, speaking is not in the least way tested all through learners' twelve years of schooling. The intention, what the government had when they introduced communicative English with an aim at integrating four skills into the curriculum, has remained half done and unaccomplished as one of the four basic skills is being given less importance. Introducing oral test to the students of school and college levels and assessing their proficiency of speaking are time demanding tasks. Once oral test is incorporated into the SSC and HSC levels, students will feel the urge to develop speaking skill at least for the exam purpose. Recommendation is that learners need to appear in viva after half yearly and annual exams, that is twice a year, but the more, the better.

2. If I do not sound idealistic, can I offer to the introduction of another English book, besides the existing one, devoting to situational and conversational English. In conversational classes, students will have the chances to interact meaningfully in pairs and groups and how to cope with different uncertain situations with the range of language, structure, and vocabulary available to them. To expedite speaking, at each college, conversation club can be set up. Students can meet in groups or pairs in club to practice unstructured communication in the form of conversation with the direct supervision of the teachers. However, the success of conversation club depends on the 
expertise of teaching. If the teachers are not efficient ones, the efforts of conversation will be futile and go in vain. For the club to be most effective, a careful planning is needed on part of the teachers. Contents of conversation classes must reflect contexts that conform to our own culture and wide enough to contribute for a large number of students. At the same time, the politeness conventions of English culture and social and cultural rules applied to each context are needed to be learned by our learners.

3. Teachers can play the crucial role to develop speaking skills within the classroom. In the class room, his/her first task will be to make students open up their mouths. Once learners have gained minimal confidence, it is easier for them to move onto next stage. Group, pair work and individual presentation are often suggested for the improvement of speaking when class size is small. In the context of Bangladesh, our class size is abnormally large and it is not possible to assign all students to group and pair works within the stipulated time. Having this situation, while an English class consists of 150 students, the teachers can divide the whole number of students into groups like A, B, C, D, etc. and assign each of the groups to group presentations. However, topics of the presentation must be given beforehand so that groups can take necessary preparation before the class and the teacher can cope with limited time. At the same time, teachers can distribute responsibilities among the group members; some will prepare the speech outside the class and some will present inside the class. However, an expert handling of situation is required on part of the teachers to ensure that while one group is speaking, another group or the rest of the students are not talking to each other or interrupting 
the speaking activities rather they are keeping mum and listening to their peers, if they have anything to ask, surely they can do it but once the speech is over. It is the teachers' responsibility to make sure that extroverts do not dominate the introverts. Sometimes, less confident students should be given the most chances in the classroom activities and for the shy students, special situation can be created where they have to talk more. Teacher will take an encouraging attitude rather than a correcting one to facilitate students' performance, creating a reassuring environment in the classroom so that every student feels at home.

4. To remove the fear of English from the minds of young learners, teachers must give them constant positive reinforcement and help them overcome their reticence. If a learner finds the class teacher is friendly and everything is favorable to them, s/he tends to take risks and as a result, speaking accelerates.

5. Providing well trained and insightful teachers in the speaking classes will solve the problems by half. Efforts must be made that no untrained teacher is going to class, specially speaking class without their prior knowledge of speaking skill or training on how to handle different speaking situations. During preservice training, they are to be familiarized with various speaking activities that are of common interest among the students all over the world and will prove useful to their real life situations. And, necessary in-service training is to be provided to ensure that teachers are properly implementing different speaking tasks in the class.

6. Students' access to language laboratory equipped with all modern facilities will expedite their proficiency of speaking. 
Language lab will make them familiar with phonetic and phonological features and various expressions produced by native speakers. But, setting language lab requires enough funding and at present, it is a far cry whereas many of our educational institutions lack necessary infrastructures and logistic supports. However, Government's long-term planning and vision to set up language lab in each school and college can materialize this seemingly impossible task into practice.

Now the question is, "what objectives should the teachers aim at, fluency or accuracy, in selecting course content of speaking? Both accuracy and fluency are important. One is not complement to other. The concerned authority should create a balance between accuracy and fluency activities in the course content. For beginners, speaking activity must be focused on thorough drilling of language forms and sequences (Rivers 195), so that the students' knowledge of grammar, pronunciation, phonological features and vocabulary can be developed. The purpose of this accuracy activity is to develop the knowledge and skills of the learners' for participating actively outside the class in a 'freer communicatively oriented activity' (Hedge 273) which is awaiting them. In Brumfit's view, 'fluency activities will give students the opportunity to produce and understand items, which they have gradually acquired during activities focused on linguistic form, which he calls accuracy work' (qtd in Hedge 58) Through in-house practices, learners would be better able to make use of any language resources and choose appropriate language for expressing ideas and opinions to meet their needs and demands outside the classes, in real world.

Speaking is a skill which deserves attention at secondary and higher secondary every bit as much as possible. It is vital to communication. Our learners often need to be able to speak with 
confidence to carry out many of their transactions. Inside the classes, tremendous responsibilities go to teachers, but they are likely to be treated in a more positive way. Communicative Language Teaching in Bangladesh's ELT would be a failure if our learners cannot meet the challenges stemmed from speaking problems. So, in order to develop speaking skill, not only learners and teachers, but also the society, families, the education system, and all parties concerned, should work together to contribute to a more communication- friendly environment.

\section{Works Cited}

Brumfit, C. J. (Ed.). Communicative Methodology in Language

Teaching. Cambridge: Cambridge University Press, 1984.

English for Today. For classes 11-12. Dhaka: NCTB, 2001.

Harmer, Jeremy. The Practice of English Language Teaching. Edinburg

Gate: Pearson Education Limited, 2001.

Hedge, Tricia. Teaching and Learning in the Language Class. Oxford:

Oxford University Press, 2000.

Rivers, Wilga M. Teaching Foreign Language Skills. Chicago: University of Chicago Press, 1981.

Skehan, P. “A framework for the implementation of task-based instruction." Applied Linguistics 17.1(1996): 36-62. 